
para uma Vida Minimalista e os Impactos no Consumo.

ISSN: 2526-7884
Editor: Prof. Dr. Marconi Freitas da Costa

E-mail: cbr@ufpe.br
Avaliação: Double blind review

Recebido: 12 de junho, 2020

Aceito: 24 de novembro, 2020

\title{
MOTIVAÇÕES PARA UMA VIDA MINIMALISTA E OS IMPACTOS NO CONSUMO
}

\author{
Motivations for a Minimalist Lifestyle and its Impact on Consumption
}

\author{
Juliana de Farias Fernandes Oliveira ${ }^{1}$ \\ ORCID: https://orcid.org/0000-0002-7427-7331 \\ E-mail: julianafernandes884@gmail.com \\ Renata Céli Moreira da Silva Paula ${ }^{1}$ \\ ORCID: https://orcid.org/0000-0001-6041-3390 \\ E-mail: renata.celi@gmail.com
}

${ }^{1}$ Universidade Federal Fluminense, Macaé, Rio de Janeiro, Brasil

\begin{abstract}
Resumo
Diversos estudos têm debatido sobre as consequências do consumo, como os impactos ambientais e sociais. Esses estudos geram reflexões e, com isso, existem pessoas que estão mudando seus modos de viver em prol de um mundo melhor ou de uma vida com mais felicidade e qualidade. Um exemplo são as pessoas que vão na direção oposta ao consumo, buscando um estilo de vida minimalista. 0 objetivo do trabalho foi investigar quais são as motivações para as pessoas buscarem uma vida minimalista e quais são os impactos no consumo. Foram feitas entrevistas em profundidade com dez adeptos do minimalismo. As motivações relatadas foram principalmente de cunho pessoal, como busca pela liberdade, felicidade
\end{abstract}

\begin{abstract}
Many studies show the consequences of consumption and its environmental and social impacts. In this context, there are people changing their lifestyle due to a better world or a life with more happiness and quality. One of these movements is minimalism. This study investigated what motivates consumers to adopt Minimalist lifestyle and its impact on consumption. In-depth interviews with ten minimalists were conducted. The results suggest that the motivation for a minimalist lifestyle is personal. The major reasons are the quest for freedom and happiness, the wish of making better use of time and money. Joining the minimalist lifestyle brings big changes in the consumption, affecting the way of dressing, moving, residing and so the way
\end{abstract}


e desejo de melhor utilização do tempo e dinheiro. Aderir ao estilo de vida minimalista leva a grandes mudanças no consumo que afetam a forma de se vestir, se locomover, morar e até mesmo a forma como se dão os relacionamentos intrapessoais e interpessoais. Foram relatados benefícios ao adotar o minimalismo. Porém, os entrevistados citaram dificuldades, como a falta de compreensão de amigos e familiares. Apesar das dificuldades, eles sentem que vale a pena aderir ao minimalismo, pois se sentem mais felizes e com uma vida com mais propósito.

Palavras-chave: Minimalismo, Anticonsumo, Simplicidade Voluntária. of relating either intrapersonal or interpersonal relationships. There were many noticeable benefits by having a minimalist lifestyle. However, there were also a few negative points, such as a lack of understanding by friends and family, who are more consumer oriented. Despite the difficulties, the minimalists feel that it is worth to adopt this lifestyle: they feel happier and believe they are living a meaningful life.

Keywords: Minimalism, Anti-consumption, Voluntary Simplicity

\section{INTRODUÇÃO}

Diversos autores relatam que vivemos uma sociedade pautada no consumo. Baudrillard (2008) ressaltou a existência do termo "Sociedade de Consumo", onde os indivíduos buscam por meio do consumo obter uma diferenciação social e uma significação. 0 autor aponta que o consumo de bens é algo tão valorizado pelos indivíduos que "faz com que o essencial esteja sempre além do indispensável" (p. 42). Lipovetsky (2006) menciona ainda a existência do hiperconsumo, fase em que se encontra a sociedade. $\mathrm{O}$ fenômeno do hiperconsumo está presente no mundo, onde consumir se torna algo urgente. Como consequência, é possível comprar produtos a qualquer hora do dia, já que existem muitas opções disponíveis para suprir essa necessidade de urgência e imediatismo no consumo.

Por outro lado, é possível encontrar paradoxos na sociedade de consumo, pois apesar de se ter pontos positivos com o amplo acesso a bens, existe o outro lado, que é caracterizado por questões negativas como impactos ambientais, estresse, depressão, dentre outros (Baudrillard, 2008). A questão das consequências ambientais e sociais do consumo tem sido amplamente debatida em diversos meios, seja acadêmico, na mídia, em diversas instituições e organizações e no dia a dia. Esse tem sido um tema colocado como importante na pauta das discussões sobre o futuro do planeta e como isso pode impactar a vida, o comportamento e o mundo. Para se ter uma ideia dos impactos ambientais, aproximadamente oito milhões de toneladas de lixo plástico são jogados nos mares e oceanos todo ano e grande parte desse lixo em ambiente aquático vem dos bens descartados de forma indevida, lixos jogados em rios que desaguam nos mares, nos esgotos que são descarregados nos oceanos ou em lixeiras perto dos mares. Alguns países estão buscando banir ou diminuir drasticamente o uso de plástico e repensando em como utilizar os recursos de maneira mais sustentável (The Orion Publish Group, 2019).

Todos esses estudos geram reflexões e, com isso, existem pessoas que estão mudando seus modos de viver em prol de um mundo melhor ou simplesmente de uma vida individual com mais felicidade e qualidade. Um exemplo são as pessoas que vão na direção oposta ao consumo e que buscam ter um estilo de vida minimalista, que é um tipo de anticonsumo. Os adeptos do estilo de vida minimalista vão na contramão do consumismo, optando por reduzir seus padrões de consumo de forma geral (Negretto, 2013; Mendonça et al., 2019).

Existem algumas pesquisas já publicadas por autores nacionais e internacionais que esclarecem o conceito do minimalismo, suas raízes históricas e como as pessoas o praticam (Negretto, 2013; Mendonça et al., 2019). Porém, esses estudos acadêmicos na área de marketing ainda são 
poucos. 0 foco das pesquisas em marketing está, em sua maior parte, no fenômeno do consumo de produtos e serviços e não o contrário.

Entretanto, o minimalismo e outros tipos de anticonsumo vêm chamando atenção das pessoas pelo mundo. Um exemplo é um documentário existente no Netflix sobre Minimalismo que tem feito muito sucesso (Almeida, 2017). Candido (2016) também cita o movimento chamado Slow Food, que é uma reflexão sobre o modo de vida da sociedade Fast Food, levando as pessoas a repensarem a forma de se alimentar, para ter consciência da importância de uma alimentação saudável com a valorização de produtores locais. Esse movimento já tem muitos adeptos pelo mundo e é outro exemplo de questionamento e ação contra comportamento "imposto" pela sociedade de consumo. Podem ser citados outros movimentos anticonsumo como o Buy Nothing Day (Dia de não comprar nada), a Hora do Planeta promovida pela ONG WWF para reflexão sobre os impactos globais (Candido, 2016), o Freganismo, movimento que tem o objetivo de reduzir impactos causados no mundo por meio do compartilhamento de recursos, alimentação vegana e redução dos níveis de consumo (Pentina \& Amos, 2011), dentre outros movimentos.

Autores têm chamado atenção sobre a importância do estudo do anticonsumo pelo marketing, pois este pode trazer uma nova perspectiva sobre os fenômenos do consumo (Chatzidakis \& Lee, 2013). De acordo com Hogg et al. (2009), o anticonsumo pode se manifestar de diferentes formas, como por meio da resistência ao consumo ou rejeição ao consumo. Os autores mencionam que os gostos dos indivíduos são influenciados por três fatores: o nível individual (a individualidade do consumidor), o ambiente social (formado pelas interações, pertencimento e aceitação em grupos de referência, etc) e o marketing. Essas influências podem interferir no comportamento de consumo ou anticonsumo. Iyer e Muncy (2009) citam quatro tipos de anticonsumidores: aqueles que estão preocupados com os impactos ambientais causados pelo consumo; os ativistas; os antileais e os simplificadores. Estes últimos estão em busca de uma vida com mais simplicidade, como exemplo os minimalistas.

Nesse contexto, é possível perceber que o estudo de movimentos anticonsumo torna-se importante, já que tem se tornado uma realidade com potencial de crescimento. Dessa maneira, este trabalho buscou investigar o tema do minimalismo, que é uma das formas de prática de anticonsumo. 0 objetivo do presente trabalho foi investigar quais são as motivações para as pessoas buscarem uma vida minimalista e os impactos no consumo. No contexto plural de nossa sociedade, é interessante que pessoas diversas procurem por um objetivo comum que vai contra o estilo de vida que é enaltecido. Por este motivo, este estudo buscou entender os porquês motivacionais dos adeptos do consumo minimalista, contribuindo para os estudos do anticonsumo.

\section{REVISÃO DA LITERATURA \\ Minimalismo}

O movimento de uma vida mais simples não é algo novo. Existiram líderes - intelectuais, espirituais - que viveram de forma simples e inspiram indivíduos até hoje (Buell, 2005). Rojas e Mocarzel (2015) fizeram uma comparação histórica entre o minimalismo na arte e o minimalismo na vida material. Em relação à arte, o minimalismo foi um movimento bastante difundido, tendo muitos artistas influenciadores. Porém, em relação às questões materiais de dia a dia, o minimalismo ainda carece de investigação e arcabouços teóricos.

0 estilo de vida minimalista envolve a redução do consumo de forma geral e há muitas formas de colocá-lo em prática: redução da compra de bens, reaproveitamento dos bens que já possuem dando novas funções a eles ou reformando-os, desapegando de alguns objetos, dentre outros (Mendonça et al., 2019). Puls e Becker (2018) ressaltam que:

Descobrir o propósito de cada um significa descobrir as coisas que mais importam, sendo esse um dos principais intuitos dos minimalistas. Para essas pessoas, o consumo exacerbado é uma forma de atraso, é ocupar um espaço com coisas desnecessárias que poderia estar sendo mais bem aproveitado. Pode-se deduzir, neste caso, que o consumismo passa a ser um impedimento 
à liberdade, pois muitas pessoas se tornam escravas de consumo por não satisfazerem seus impulsos e desejos (Puls \& Becker, 2018, p. 105).

Rojas e Mocarzel (2015) esclarecem que a ideia do minimalismo se desenvolve em torno do conceito de simplicidade voluntária, que, de acordo com Iyer e Muncy (2009), é a adoção de uma vida mais simples. Para Candido (2016), "a escolha por uma vida simples é um processo consciente que tem como propósito uma melhor qualidade de vida" (p. 34).

O minimalismo e a simplicidade voluntária são tratados muitas vezes como sinônimos. Um dos artigos seminais sobre simplicidade voluntária foi publicado em 1977 por Elgin e Mitchell que definem a vida simples como sendo "aparentemente simples e interiormente rica" (Elgin \& Mitchell, 1977, p. 2). É uma escolha voluntária, ou seja, o indivíduo passa a viver de forma simples por opção e não por obrigação ou por questões de restrição financeira (Etzioni, 1998). Posteriormente, Elgin (2012) publicou um novo livro sobre simplicidade voluntária, tendo como objetivo divulgar o estilo de vida como uma das soluções para os problemas ambientais, mencionando que a adoção de uma vida mais simples que vai na contramão do consumismo ajudaria o planeta em relação aos danos ambientais que o excesso de consumo vem causando.

De acordo com Iyer e Muncy (2009), os adotantes da vida simples, que os autores chamam de simplifiers, são um tipo de anticonsumidores. Trata-se de um tipo de anticonsumo que busca reduzir o consumo de forma geral, ou seja, não é deixar de comprar uma marca ou produto específico, e sim reduzir o consumo como um todo. Os autores mencionam que os anticonsumidores podem ser aqueles que deixam de comprar um produto ou marca específica ou aqueles que reduzem o consumo geral. Além disso, eles podem ter motivações individuais ou sociais. No caso do minimalismo, para Iyer e Muncy (2009), seriam motivações de interesses pessoais.

No estudo de Chatzidakis e Lee (2013), são citadas algumas razões contra o consumo, como: questões éticas e ambientais, questões de resistência e questões simbólicas. No contexto do anticonsumo, Cherrier (2009) sublinhou a existência de duas identidades de anticonsumidores: "a identidade de herói" e a "identidade de projeto". A "identidade de herói" está relacionada a se ver como um agente capaz de mudar o mundo por meio do anticonsumo. Já a "identidade de projeto" está mais associada a uma mudança individual, um foco na transformação pessoal. Esses resultados mostram que os anticonsumidores podem ter identidade diferentes - com foco no pessoal ou social. Enquanto alguns focam mais em uma mudança pessoal, outros se veem como pessoas capazes de mudar o mundo para melhor com seus novos hábitos de anticonsumo. Essas identidades poderiam ser aplicadas no estudo específico dos indivíduos minimalistas, pois, apesar de Iyer e Muncy (2009) mencionarem que os interesses dos adotantes da vida simples são pessoais, outros autores ressaltam que também podem envolver questões mais amplas, como a preocupação ambiental (Elgin, 2012).

Segundo Negretto (2013), o que se torna relevante para o estilo de vida minimalista é a reflexão, a liberdade de escolhas, e não quantas ou quais coisas uma pessoa possui, já que não existe regra a este respeito. Autores mencionam essa questão de não haver regras em relação à vida simples ou minimalismo. Isso pode depender de vários fatores, pois o que é essencial para um indivíduo pode não ser necessário para outro, portanto, não existe um padrão e uma "receita de bolo" para se adotar uma vida simples (Negretto, 2013; Puls \& Becker, 2018). Rojas e Mocarzel (2015) ressaltam que os minimalistas começam o processo reduzindo o consumo de forma geral e, em seguida, vão expandindo a simplicidade para outros setores da vida como por exemplo no trabalho e nas relações. Outros autores mencionam essa simplificação da vida de forma geral, envolvendo o trabalho, a residência, o consumo de bens, etc (Silva \& Hor-Meyll, 2016).

O minimalismo é um movimento que tem crescido e que tem a internet como lugar central de propagação e discussão (Rojas \& Mocarzel, 2015). Muitos adeptos da vida simples têm usado comunidades virtuais para interagir com outros adotantes (Silva \& Hor-Meyll, 2016). 0 estudo de Silva et al. (2012), por exemplo, foi feito unicamente com adotantes da vida simples que se reúnem na internet para conversar e trocar ideias. 0 uso da internet é mencionado também nos estudos de anticonsumo. Um exemplo é o artigo de Hollenbeck e Zinkhan (2006) que cita a criação de comunidades virtuais antimarca. 
Ao adotar uma vida mais simples, as pessoas passam por diversas transformações. Silva e HorMeyll (2016) relatam algumas mudanças, tais como: vida profissional (busca por um trabalho com propósito), consumo de produtos (grande redução no consumo de bens de forma geral, dando preferência para produtos que tenham qualidade e que durem mais, para não precisar comprar em grande quantidade ou grande frequência), alimentação mais natural, preocupação com o descarte de produtos, casas menores e mais simples, valorização de experiências (o que pode gerar um consumo de serviços pagos ou gratuitos, como atividades culturais) e maior consciência e preocupação com a sociedade e o meio ambiente.

Silva et al. (2012) também realizaram uma pesquisa com pessoas que estão em busca da simplicidade e viram que as principais mudanças na vida desses indivíduos foram tanto em questões práticas e tangíveis (redução do consumo de bens e consumo mais consciente) como em questões intangíveis (busca de mais tempo para contemplar a natureza, mudança de valores, maior valorização da vida e do que é importante de verdade).

Sobreira et al. (2018) realizaram uma pesquisa com indivíduos que adotaram o conceito de armário-cápsula. Armário-cápsula é um conceito baseado na adoção de um armário com poucas peças de roupa e que serão usadas por três meses. Após esses meses, o armário-cápsula é renovado e passase a utilizar uma nova coleção de roupas. Porém, durante os meses que o armário-cápsula está em uso, não se deve comprar novas peças, somente no momento de renovação do armário-cápsula. Os autores encontraram nos resultados da pesquisa que os adotantes do armário-cápsula possuem valores ligados à vida simples. Buscam uma maior liberdade e possuem uma consciência ambiental. Ao adotar o armário-cápsula passam a ter mais conscientização e reflexão sobre o consumismo e o que realmente é necessário para viver.

\section{Motivação para se tornar Minimalista}

As motivações para se adotar uma vida simples podem variar de pessoa para pessoa, como já foi relatado por alguns autores (Zavestoski, 2002; Negretto, 2013; Candido, 2016; Puls \& Becker, 2018). Zavestoski (2002) mostrou que as motivações de forma geral podem, inclusive, se alterar de acordo com os períodos históricos vividos. Existem épocas em que as motivações para se ter uma vida mais simples giram em torno de questões religiosas e de espiritualidade e que isso tem sido mudado para causas mais pessoais como a busca pela realização e propósito de vida e a diminuição do estresse que muitas pessoas têm relatado viver.

Negretto (2013) considera motivações pessoais e individualistas que levam o indivíduo a aderir ao estilo de vida minimalista. Algumas destas motivações são a vontade de obter alívio por se livrar das pressões sociais do consumismo, autoconhecimento e maior controle sobre a própria vida (Negretto, 2013). Na mesma linha, Silva e Hor-Meyll (2016) documentaram algumas motivações que levavam as pessoas a aderirem a este estilo de vida, algumas delas foram: insatisfação com o trabalho, retorno aos valores de simplicidade ensinados e vividos pela família, insatisfação com o consumo exagerado, libertação das diversas pressões impostas pela sociedade e busca por mais tempo para se dedicar ao lazer. De acordo com a pesquisa de Silva e Hor-Meyll (2006), os adeptos da vida simples optam por esse estilo de vida por questões pessoais, assim como foi relatado por Negretto (2013).

Entretanto, posteriormente, ao vivenciar a simplicidade voluntária na prática, as pessoas acabam incorporando outros valores ligados à sociedade e passam a ter maior consciência ambiental e social, valores estes que são incorporados aos seus comportamentos e que impactam também a forma de consumo. Isso leva a um consumo mais consciente e com menos impactos ambientais, pensando em reduzir o desperdício, consumir o necessário e conscientizando-se em relação ao descarte de produtos - redução do lixo, reciclagem, reaproveitamento de objetos, doações, compra de produtos usados, troca de produtos, etc (Silva \& Hor-Meyll, 2006). Negretto (2013) reforça este ponto dizendo que os minimalistas sabem dos impactos ambientais que o mundo está vivendo e possuem uma consciência ambiental. Porém, para Negretto (2013), esta não é a principal pauta do minimalismo, apesar de estar presente. 0 minimalismo é movido principalmente por interesses individuais de uma busca por uma vida com maior propósito: "mudar a forma como consumimos para melhorarmos nossas vidas" (p. 74). 
Por outro lado, Oates et al. (2008) ressaltam que as motivações podem ser não somente de origem pessoal (como exemplo a diminuição do estresse no dia a dia), mas também ambiental, ética e social. Como mencionado anteriormente, para Iyer e Muncy (2009), a vida simples é adotada por motivos pessoais. Outros estudos apontam para razões ambientais ou sociais (Elgin, 2012), como exemplo, o estudo de Shaw e Newholm (2002), que cita motivações éticas e altruístas. Portanto, ainda é uma questão que gera debates e não possui um consenso.

Outro ponto abordado em estudo sobre vida simples é a felicidade. Muitas pessoas se sentem insatisfeitas e frustradas mediante comportamentos de consumo exagerado, pressão da sociedade por consumir e ter cada vez mais bens, que só trazem uma satisfação momentânea, que rapidamente desaparece (Silva \& Hor-Meyll, 2016). É o que Baudrillard (2008) chamou de paradoxo da sociedade de consumo. Estudos têm mostrado que a felicidade prometida pelo consumo não necessariamente é alcançada (Csikszentmihalyi, 1999; Ahuvia, 2008). Rojas e Mocarzel (2015) ressaltam que as pessoas acabam buscando o minimalismo por estarem cansadas da sociedade de consumo que pressiona por um consumismo que não gera qualidade de vida. Portanto, ao buscar uma vida mais simples e minimalista, muitas pessoas buscam alcançar uma vida com mais sentido e mais felicidade (Zavestoski, 2002; Silva et al., 2012).

Puls e Becker (2018) falam sobre o maior benefício do minimalismo: a liberdade. As autoras expõem que aderir a uma vida minimalista leva à libertação de tudo que é excesso, o que abre espaço para focar naquilo que é essencial, ou seja: "encontrar a felicidade e a realização" (p. 102). Etzioni (1998) também menciona a felicidade que as pessoas sentem ao simplificarem suas vidas. No estudo de Mendonça et al. (2019), foi citado o benefício de "atingir calma e paz interior" (p. 9).

Puls e Becker (2018) corroboram este ponto ao citar que algumas pessoas buscam o minimalismo com a intenção de entender quais coisas são mais importantes para elas, no sentido de descobrir seu propósito de vida. Johnston e Burton (2003) também sublinham a busca por propósito de vida e crescimento pessoal. Silva e Hor-Meyll (2016) mencionam que os praticantes da vida simples são pessoas que se diferenciam pelo não consumo, enquanto as outras pessoas, de forma geral, buscam no consumo a diferenciação.

Alguns autores discutiram sobre os benefícios de adotar o minimalismo, segundo a visão dos adotantes. De acordo com os estudos de Silva et al. (2012), os principais benefícios para a adoção da vida simples podem ser vistos na Tabela 1, a seguir:

Tabela 1

Benefícios da vida simples

\begin{tabular}{l|l}
\hline \multicolumn{1}{c|}{ Benefícios pessoais } & \multicolumn{1}{c}{ Benefícios sociais } \\
\hline Felicidade & Impactos positivos no mundo \\
\hline Saúde & Maior compromisso com o mundo \\
\hline Equilíbrio & \\
\hline Paz & \\
\hline Preocupação com o essencial & \\
\hline \multicolumn{2}{l}{ Fonte: Silva et al. (2012), adaptado pelas autoras }
\end{tabular}

Silva e Hor-Meyll (2016) encontraram em seus resultados as consequências de se adotar uma vida mais simples, tais como: felicidade, economia de tempo (tempo este que será gasto em atividades mais prazerosas) e de dinheiro (já que não há gastos com produtos que não são necessários) e liberdade. Porém, existem estudos que também falam do outro lado da adoção de uma vida mais simples, pois é como se fosse uma vida "na contramão", já que ainda são poucas as pessoas que caminham nessa direção. Portanto, muitas vezes, os minimalistas são incompreendidos (Candido, 2016; Silva \& Hor-Meyll, 2016).

Silva et al. (2012) ressaltam que:

A dificuldade é percebida sob dois pontos de vista: o individual e o social. 0 individual diz respeito à dificuldade de mudar seus hábitos. 0 social diz respeito à relação do indivíduo com a 
sociedade. Como a sociedade como um todo não adota esta ideia, o indivíduo acaba tendo que

"remar contra a maré", o que constitui um fator complicador (p. 62).

\section{MÉTODO}

O presente artigo trata de uma pesquisa exploratória. De acordo com Malhotra (2012), "o objetivo da pesquisa exploratória é explorar ou fazer uma busca em um problema ou em uma situação a fim de oferecer informações e maior compreensão" (p. 59). A pesquisa foi realizada investigando diversos aspectos do minimalismo que foram orientados pelos objetivos deste estudo.

A pesquisa de campo foi realizada por meio de entrevista em profundidade, uma das técnicas da pesquisa qualitativa. "Na abordagem qualitativa, o que se pretende, além de conhecer as opiniões das pessoas sobre determinado tema, é entender as motivações, os significados e os valores que sustentam as opiniões e as visões de mundo" (Fraser \& Gondim, 2004, p. 8). Dentre os procedimentos de pesquisa qualitativa, optou-se pelas entrevistas em profundidade, por serem adequadas ao problema de pesquisa. A entrevista em profundidade é uma técnica de "entrevista não estruturada, direta, pessoal, em que um único respondente é sondado por um único entrevistador (...)." (Malhotra, 2012, p. 121).

A coleta de dados foi realizada por meio de entrevistas em profundidade com participantes de um grupo sobre minimalismo no Facebook. As entrevistas foram guiadas por um roteiro semiestruturado que abordava os seguintes temas: o que é minimalismo, motivações para a adoção do minimalismo, principais mudanças nos hábitos e consumo, benefícios e dificuldades da vida minimalista. Uma das pesquisadoras, por meio do seu perfil na rede social Facebook, começou a integrar uma comunidade virtual chamada "Minimalismo". A comunidade é fechada, ou seja, para entrar, é preciso enviar uma solicitação de participação e aguardar a autorização. 0 grupo Minimalismo possui cerca de trinta e quatro mil membros. Diariamente as pessoas postam dúvidas e pedem dicas sobre diversos temas ligados ao minimalismo.

Após pedir autorização para o administrador da comunidade virtual, foi feita uma postagem aberta no grupo recrutando entrevistados. Algumas pessoas se mostraram dispostas a participar voluntariamente da entrevista. No total, foram entrevistadas 10 pessoas. As entrevistas ocorreram no período de novembro de 2018 e foram feitas por meio de aplicativos de conversa online - chats de mensagens, a critério do entrevistado. Existem autores que defendem esse tipo de entrevista em profundidade online, visto que nos dias de hoje, as pessoas encontram-se conectadas a todo tempo, sendo, portanto, um novo meio de coletar dados (Nicolaci-da-Costa et al., 2009).

Após as entrevistas, os dados foram analisados. Buscou-se analisar as entrevistas como um todo, buscando pontos em comum e diferenças, e a análise das entrevistas individuais de forma detalhada, como sugerem Nicolaci-da-Costa et al. (2009). Além disso, os resultados foram comparados com a literatura encontrando pontos de convergência e divergência. Os nomes dos entrevistados foram trocados por siglas para preservação de sua identidade. Para identificar os homens foi utilizada a inicial " $H$ " e para as mulheres a inicial " $M$ ".

\section{ANÁLISE DOS RESULTADOS}

\section{Perfil dos Entrevistados}

As entrevistas foram realizadas com oito voluntárias do sexo feminino e dois voluntários do sexo masculino. As idades variaram entre 23 e 43 anos. Cinco das 10 pessoas entrevistadas possuem filhos e três afirmaram morar sozinhas. Os voluntários são todos brasileiros residentes em diversas cidades do país.

\section{O Que é o Estilo de Vida Minimalista para os Entrevistados}

Os entrevistados relacionaram primeiramente o estilo de vida minimalista à mudança nos hábitos de consumo. Todos os participantes responderam que se consideram minimalistas por consumir pouco e evitar possuir coisas em excesso. Os participantes foram unânimes em afirmar que ter um estilo de vida minimalista é mudar a forma de se relacionar com o consumo e até de pensar do indivíduo. Alguns afirmaram que é buscar uma vida totalmente livre de supérfulos, enquanto outros 
acreditam que há espaço para pequenos luxos algumas vezes. Interessante notar que os conceitos de "luxo", "supérfluo" e "essencial" se mostraram variados nas entrevistas, assim como apontam alguns autores que mostram que cada indivíduo tem a sua percepção a respeito destas classificações (Negretto, 2013; Puls \& Becker, 2018).

Foram dadas diferentes respostas para a pergunta "Para você, o que significa ter uma vida minimalista?". A seguir, pode ser visto o depoimento do Entrevistado H1.

Viver com poucas coisas, sem excessos, permitindo alguns luxos às vezes. Um iPhone eu considero um luxo, pois tem smartphones que fazem o mesmo por $1 / 3$ do valor ou menos. Mas eu tenho um iPhone e gosto muito dele. Um carro maior pode ser um luxo se não precisamos dele, sendo que um usado e menor também serviria na maioria dos casos (Entrevistado H1).

Já a entrevistada M3 acredita que ter o estilo de vida minimalista é "viver com o básico, de forma confortável, mas sem supérfluos e excessos". A participante M8 diz que, para ela, ter um estilo de vida minimalista é gastar menos dinheiro com coisas "inúteis". M6 acrescenta que, em sua opinião, o estilo de vida minimalista é tirar o foco dos bens materiais e focar nas pessoas e no cuidado com o meio ambiente: "O estilo de vida minimalista é ter uma vida com a felicidade em aproveitar momentos e pessoas e não em ter mais coisas. E também reduzir o volume de lixo que produzimos". A entrevistada M4 afirma que ter uma vida minimalista é voltar atenção para si mesma e viver orientada pelo seu propósito e não pela mídia ou vontade de outros. Sobre o que significa ter um estilo de vida minimalista ela diz: "penso que significa olhar para o outro com mais criticidade e humanidade e viver segundo nossos próprios desejos".

A grande variedade de opiniões individuais sobre o minimalismo está de acordo com o que afirma Candido (2016) em seu estudo. Candido (2016) diz que o conceito de minimalismo não é apenas um, pois cada indivíduo irá viver o minimalismo da maneira que julgar melhor para si mesmo. A busca pela liberdade que os minimalistas tanto falam também tem a ver com essa questão de não ter padrões. Se tiver padrões, foge da liberdade. E essa libertação da pressão da sociedade é amplamente buscada por essas pessoas (Silva \& Hor-Meyll, 2016; Puls \& Becker, 2018).

\section{Motivação}

Os participantes da pesquisa de campo deixaram claro que existem diversas motivações para aderir ao estilo de vida minimalista. Ao mesmo tempo que as motivações são diferentes para cada pessoa, cada uma apresentou várias motivações. As principais motivações foram as apontadas na Tabela 2, a seguir:

Tabela 2

Motivação para Aderir ao Minimalismo

\begin{tabular}{l|l}
\hline \multicolumn{1}{c|}{ Motivações Pessoais } & \multicolumn{1}{c}{ Motivações Ambientais } \\
\hline Busca por liberdade e felicidade & Preocupação com desmatamento \\
\hline Influência da família & Preocupação com uso de recursos naturais \\
\hline Busca por mais tempo livre e dinheiro & \\
\hline
\end{tabular}

Fonte: Elaborado pelas autoras

As motivações foram divididas em motivações pessoais e motivações ambientais. Dentre as motivações pessoais estão a busca por liberdade e felicidade, influência dos familiares e a busca por mais tempo livre disponível e por mais dinheiro. Dentre as motivações ambientais estão as preocupações com o desmatamento e com os recursos naturais do planeta. Comparando os resultados do presente estudo com a literatura, enquanto alguns pesquisadores sublinham que as motivações para a prática da vida mais simples são de interesses pessoais (Iyer \& Muncy, 2009; Negretto, 2013; Silva \& Hor-Meyll, 2016), outros mencionam que também existem interesses mais amplos, como preocupações éticas e ambientais (Shaw \& Newholm, 2002; Oates et al., 2008; Elgin, 2012). A presente pesquisa encontrou resultados semelhantes a Shaw e Newholm (2002), Oates et al. (2008) e Elgin 
(2012), pois os entrevistados apresentaram motivações de natureza pessoal e ambiental. As diferentes motivações são detalhadas a seguir.

\section{Motivações Pessoais}

Alguns participantes da pesquisa afirmaram que desde a infância foram ensinados pela família sobre o valor do dinheiro e a pensar criticamente antes de adquirir qualquer produto. Estes participantes vieram de famílias com baixo poder aquisitivo e tiveram uma infância e adolescência sem luxos. Ao chegar à etapa da vida adulta, conseguiram elevar seu padrão financeiro, mas continuaram consumindo de forma contida, ou seja, menos do que a maioria de seus colegas de trabalho e amigos consomem. Os entrevistados que já vinham de uma família que praticava uma vida simples, seja pela falta de recursos ou por escolha, afirmam que tiveram seus valores familiares reforçados ao conhecer o minimalismo. Esses resultados também foram encontrados na pesquisa de Silva e Hor-Meyll (2016), que mencionaram que alguns adotantes da vida simples sentiram a necessidade de resgatar esses valores antigos da família, pois viviam uma vida simples e, em algum momento, se perderam desses valores, o que os tornou insatisfeitos com a forma que estavam conduzindo a vida.

Já os demais entrevistados, viviam uma vida de consumo com pouca reflexão e buscavam um estilo de vida que gerasse menos estresse e pressão causada pelo hiperconsumo (Negretto, 2013; Silva \& Hor-Meyll, 2016). Eles estavam em busca de uma vida leve e com praticidade. H1 diz que desde a adolescência sempre prezou pela simplicidade, buscando economizar e ter atitudes objetivas. Segundo ele, ainda não conhecia a expressão "minimalismo", mas já seguia vários pontos que o estilo de vida aborda, como comprar conscientemente e evitar desperdícios.

A entrevistada M5 avalia que gastava muito dinheiro e tempo comprando coisas que após adquirir julgava como inúteis. Passava muito tempo trabalhando para adquirir dinheiro e depois escolhendo o que comprar, além do tempo que demandava manter tudo em ordem. Quando conheceu o minimalismo através do documentário "The Minimalism", ela se identificou como consumista e percebeu que poderia dispor de mais tempo e dinheiro se mudasse seus hábitos.

A motivação "busca por mais tempo e dinheiro" foi citada pela maior parte dos entrevistados. Alguns comentam que gastavam muito dinheiro com coisas que não consideravam prioridade. Outros falam sobre gastar muito tempo organizando objetos que muitas vezes nem eram utilizados, estavam em suas casas apenas por apego. Em relação ao vestuário foi relatado que ter um excesso de peças demanda muito tempo na hora de se arrumar para algum compromisso. $\mathrm{O}$ entrevistado $\mathrm{H} 1$ relatou que possuindo apenas uma calça de boa qualidade para trabalhar, ele pode usar a mesma a semana inteira, sem se preocupar em escolher. Autores já discutiram essa questão de que o consumismo não leva a uma maior qualidade de vida (Rojas \& Mocarzel, 2015) e a adoção do minimalismo pode ajudar a alcançar uma vida com mais qualidade e tempo para fazer o que realmente é mais importante (Puls \& Becker, 2018).

Duas participantes relataram ter aderido ao minimalismo em momentos chave de suas vidas. M1 disse acreditar que o término de um namoro a impulsionou a efetuar uma mudança em sua vida. Foi nesta mesma época que ela conheceu o estilo de vida minimalista e se identificou com as ideias apresentadas no documentário "The Minimalism". A partir de então, ela começou a pesquisar mais e aderiu a este estilo para sua vida.

Já a participante M4 descobriu o estilo de vida quando estava vivendo um momento de grande transição: a maternidade. Ela relata que adotou o minimalismo como estilo de vida após perceber que estava vivendo a vida segundo os "padrões impostos pela sociedade" e que não estava tomando suas decisões com base em suas próprias conviç̧ões. A entrevistada M4 acredita que o estilo de vida minimalista leva o indivíduo por um caminho de mais liberdade e, consequentemente, felicidade. Sobre isto, M4 afirma: "Penso que não devemos nos importar com o que o sistema espera de nós... precisamos olhar para o essencial e invisível, dentro de nós, e escolher o lugar que desejamos ocupar no mundo, seja onde for, esse lugar é o nosso!"

O que a entrevistada M4 relata está de acordo com as descobertas da pesquisa de Silva e HorMeyll (2016) que falam sobre a "libertação da pressão da sociedade": a entrevistada percebeu que não 
estava vivendo de acordo com seus próprios sonhos e desejos e isto foi uma de suas motivações para aderir ao minimalismo. Além disso, ela relata que ficou mais feliz com a vida minimalista, indo ao encontro dos estudos que apontam que a felicidade prometida pela sociedade de consumo não necessariamente é alcançada (Csikszentmihalyi, 1999; Ahuvia, 2008).

A entrevistada M5 afirma que se sentia cansada mentalmente por ter tantos objetos com os quais se preocupar, principalmente porque costuma se mudar a cada dois anos. Ela decidiu aderir ao minimalismo para se livrar de toda esta carga e se sentir mais livre de coisas materiais e se "libertar da ansiedade que sentia". Ela sentia que o excesso de coisas a limitava de viver a vida que almejava para si. Assim como M5, a entrevistada M6 relata que decidiu aderir ao estilo de vida minimalista após perceber que era mais feliz quando tinha menos coisas com as quais se preocupar. 0 depoimento de M6 pode ser visto a seguir.

Passei 29 dias viajando com meu esposo com 2 malas, foi o período mais feliz deste ano. Quando cheguei em casa me dei conta de que tinha muita coisa e definitivamente não preciso de todas elas para ser feliz. Eu prefiro gastar meu dinheiro e energias em planejar viagens, encontro com amigos. (Entrevistada M6)

Nessa mesma linha, a entrevistada M2 cita que ao fazer um intercâmbio na Alemanha percebeu que as pessoas daquele país tinham mais liberdade para se vestir como gostam e comprar apenas o que realmente querem. Ela conta que percebeu que as pessoas pareciam estar mais preocupadas com o "ser" do que com o "ter". Mesmo que eles não se denominassem como minimalistas, as atitudes daquele povo despertaram algo novo para ela: a vontade de ter uma vida mais simples. Ela se identificou em meio aos hábitos que observava dos alemães. Puls e Becker (2018) e Negretto (2013) enriquecem este raciocínio ao pontuar que os minimalistas não buscam a felicidade em posses materiais, por acreditarem que este não é o caminho. Dessa forma, eles veem o minimalismo como um caminho para a felicidade. Ao buscar o "ser" e não o "ter", os adotantes do minimalismo podem viver uma vida "aparentemente simples e interiormente rica" (Elgin \& Mitchell, 1977, p. 2).

\section{Preocupações Ambientais}

Alguns entrevistados declararam buscar uma vida de consumo minimalista para diminuir o prejuízo que o consumo causa à natureza. Um exemplo é a declaração da participante M3 que diz que decidiu aderir ao ver que é necessário evitar o excesso de consumo para amenizar "nosso impacto no planeta". A participante também segue a filosofia de vida vegana, que tem como premissa o respeito aos animais e à natureza de forma geral. Após adotar o estilo de vida vegano, decidiu adotar também o estilo de vida minimalista. As preocupações ambientais do minimalismo podem estar relacionadas ao que Cherrier (2009) encontrou quando estudou o anticonsumo. A autora menciona que os anticonsumidores possuem duas identidades: a de herói e a de projeto. A primeira está ligada à vontade de mudar o mundo e a segunda a questões mais pessoais de transformação de si. Um questionamento que se abre é se a "identidade de herói" dos anticonsumidores também vale especificamente para os minimalistas.

Foi possível notar que esta motivação ambiental não foi apontada como principal neste estudo, nem mesmo foi citada pela maioria dos entrevistados. Porém, ela foi citada por alguns, o que mostra que é uma razão também para se adotar o minimalismo. Embora estudos como o de Iyer e Muncy (2009), Negretto (2013) e Silva e Hor-Meyll (2016) apontem que as motivações para o estilo de vida simples são de origem pessoal, outros sugerem que, além das razões pessoais, existem razões mais amplas, como sociais, éticas e ambientais (Oates et al., 2008; Elgin, 2012).

\section{Mudança de Hábitos após Aderir ao Estilo de Vida Minimalista}

Em geral, houve dois grupos percebidos na pesquisa: um composto por pessoas que consideram que foram educadas pela família a ter uma vida simples e consumir de forma consciente. Já o segundo grupo, é composto por pessoas que se consideravam consumistas e em algum momento resolveram buscar um estilo de vida diferente e acabaram encontrando o minimalismo. Todos os 
entrevistados afirmaram ter conhecido este estilo de vida pela internet, através de documentários, grupos sugeridos pelo Facebook, blogs e outros espaços virtuais. Autores já mencionaram que a internet é o principal local onde as ideias do minimalismo têm sido divulgadas e debatidas pelo mundo (Rojas \& Mocarzel, 2015).

Os entrevistados que afirmam que já viviam uma vida simples antes de conhecer o minimalismo, percebem que passaram a viver com mais propósito após conhecerem o conceito e pesquisar mais sobre o tema. Já os entrevistados, que antes se consideravam consumistas, passaram a aderir ao minimalismo pouco a pouco, começando por mudar hábitos de consumo do dia a dia, como adquirir menos roupas e outros objetos e aderir ao "destralhe". "Destralhe" ou "desapego" é um termo muito utilizado entre os consumidores minimalistas. Estes termos são usados para se referir ao descarte de bens que não estejam sendo úteis. Geralmente este descarte é feito em forma de doação ou troca com amigos. A entrevistada M4 relata que tem realizado grandes mudanças em sua vida após aderir ao estilo de vida minimalista:

Hoje eu penso com muito mais criticidade e clareza sobre a vida. Aplico o minimalismo em várias coisas na minha vida: alimentação, vestimenta, decoração, criação do meu filho, compro com muito mais responsabilidade. [...] meu filho, por exemplo, mostra que não precisa de muitas coisas que a indústria inventa.

Ela continua relatando que usa o minimalismo como parâmetro para muitas decisões em sua vida. A entrevistada conta que decidiu parar de trabalhar fora para se dedicar completamente à educação do filho e isso foi possível por adotar este estilo de vida. Ela explica que tomou essa decisão baseando-se na lógica financeira da família e também no que considera mais importante oferecer ao seu filho nos primeiros anos de sua vida: "Por essa razão, escolhi ser presente ao invés de dar presentes. Ser presente é essencial".

A entrevistada M3 avaliou que busca ter um estilo de vida minimalista até no que diz respeito a relacionamentos e experiências, buscando viver de forma alinhada com seus valores. 0 depoimento, a seguir, ilustra a visão de M3:

As amizades também são avaliadas com mais critério, o que exponho diante dos meus sentidos são coisas de utilidade para meu melhoramento pessoal, moral e espiritual. Em relação a conversas, também costumo falar (tento) assuntos de valor moral, espiritual, evitando frivolidades, fofocas, maledicências, julgamentos. Esse é um processo mais demorado (o de não comentar certos acontecimentos da vida de alguém). (Entrevistada M3)

Como pode ser visto, os entrevistados fizeram uma simplificação da vida em diversas áreas e de diversas formas. Ou seja, a vida mais simples não está ligada somente à redução do consumo de forma geral, mas também envolve outras áreas da vida, como os relacionamentos e comportamentos. Alguns autores já ressaltaram essas questões. Para Rojas e Mocarzel (2015), os adotantes do minimalismo começam o novo estilo de vida reduzindo o consumo de bens para, posteriormente, expandir a simplificação para o trabalho, as relações, etc.

\section{Mudanças nos Hábitos de Consumo}

A entrevistada M6 diz que após aderir ao estilo de vida minimalista, passou a pensar melhor antes de adquirir algo. Além disso, está sempre pensando o que pode ser descartado, até que chegue a ter apenas o que considera necessário. Ela afirma que, em relação ao consumo, é necessário reprogramar os pensamentos para minimizar as influências sociais e da mídia que "nos faz acreditar que precisamos ter para ser feliz". A participante M1 relata que desde que aderiu ao minimalismo, evita qualquer compra de excessos:

Evitar compras desnecessárias, coisas que se acumulam, não possuem funcionalidade ou até possuem alguma que é irrelevante. Isso me economiza tempo de vida. Gasta-se menos tempo 
arrumando menos coisas, menos dinheiro e, consequentemente, sobra mais tempo e mais dinheiro para aproveitar com as coisas que realmente importam. (Entrevistada M1)

Alguns entrevistados afirmaram preferir morar em residências alugadas do que ter a sensação de estarem "presos" a um lugar fixo e ter que arcar com uma dívida tão longa como um financiamento de um imóvel. Assim, podem se mudar conforme sua vontade ou necessidade. Ainda em relação à moradia, o entrevistado $\mathrm{H} 1$ descreveu como muitos de seus hábitos mudaram, até mesmo algumas ambições não são mais as mesmas, como o antigo sonho de ter uma biblioteca: "Antes [de aderir ao estilo de vida minimalista, eu] sonhava em ter uma biblioteca, mas comprei um Kindle [aparelho eletrônico para ler $e$-books] e doei uns 30 livros para biblioteca da empresa". Ele relata que sempre busca consumir a medida do que precisa, só comprando coisas novas para substituir as antigas, ao invés de ter vários objetos com mesma função.

Tenho uma boa calça jeans (discreta) para trabalhar e uso a mesma a semana inteira, trabalho administrativo, não suja. Não preciso me preocupar em escolher. As camisas são uniforme, então [tenho] várias. Um tênis para trabalhar outro para sair, peças chave, sem erro, sem preocupação. Quem precisa se preocupar com essas coisinhas, é menos satisfeito (Entrevistado H1).

Os entrevistados comentaram que costumam avaliar cautelosamente se a necessidade de adquirir determinado item é real quando vão às compras. Eles afirmam que muitas vezes as pessoas são levadas a consumir por impulso, seja para "ostentar" ou preencher carências emocionais em alguma área da vida ou comprar como válvula de escape para o estresse e a ansiedade. Planejando bem as compras, eles buscam fugir de compras que não sejam necessárias. Nas ocasiões de compra, disseram optar por comprar produtos de segunda mão ou produtos de alta qualidade, que possam durar mais tempo, como foi visto em outros estudos (Silva \& Hor-Meyll, 2016).

As mudanças adotadas foram no sentindo de passar a consumir de forma mais planejada, optando por produtos de melhor qualidade, mesmo que com preço mais elevado. Além de passar a ter hábitos de alimentação mais caseiros, ao invés de comprar comidas já prontas, por exemplo. Percebese também a diminuição da quantidade de compras realizadas. Esses achados também estão presentes na pesquisa de Silva e Hor-Meyll (2016).

\section{Benefícios}

Para M3, ter uma vida minimalista é sinônimo de viver melhor, ser mais com menos. Todos os entrevistados afirmaram perceber muitos benefícios na vida minimalista. 0 depoimento de M3, a seguir, ilustra alguns deles.

Bom, economizei grana. Mas o melhor mesmo tem sido a mudança na forma de ver o mundo e a natureza. Ampliou meu senso de responsabilidade com o cuidado com o planeta. Eu me sinto melhor em ser assim, melhor comigo mesma, como se não devesse tanto a Deus e ao todo. (Entrevistada M3)

Foi muito citado nas entrevistas como característica do minimalismo, ajudar a compreender a identidade do indivíduo, de se perceber como singular. Segundo M3, ter o seu mínimo necessário bem definido ajuda a dar norte à vida e à própria identidade, mesmo que de forma temporária ou transitória. Outro benefício muito citado foi uma menor dependência dos bens materiais. A entrevistada M6 citou o fato de estar menos rodeada de lembranças que são atribuídas aos objetos como uma vantagem do consumo minimalista. Ela busca descartar objetos que não trazem sentimentos positivos.

Vários participantes disseram se sentir menos "pertencentes" às coisas que possuíam e mais donos do próprio tempo, do dinheiro, mais donos da própria decisão, assim como a participante M3 que disse que após aderir ao minimalismo se sente mais apta a doar objetos que não usa mais e até a 
receber doações de outros, como forma de gerar menos demanda de produção de produtos. Ao receber doações e, consequentemente, comprar menos, outro benefício é percebido: a economia de dinheiro. A economia de dinheiro foi citada por todos os participantes como um grande benefício do minimalismo. A entrevistada M6 vê como benefício do estilo de vida minimalista ter mais dinheiro e tempo para gastar com o que mais gosta de fazer, como viajar e passar momentos com os amigos. Portanto, muitos passaram a adotar o minimalismo com a motivação de ter mais tempo e dinheiro e, de fato, conseguiram conquistar esses objetivos. E passaram a usar esse tempo e dinheiro em busca de experiências prazerosas (Silva \& Hor-Meyll, 2016).

Uma vida mais "leve" no sentido de ter menos responsabilidades é também citada por muitos dos entrevistados como um ponto positivo do minimalismo. Segundo eles, o apego aos bens materiais restringe a liberdade, uma vez que cada pessoa deve se sentir responsável por tudo que compra e muitas destas compras geram mais estresse e perda de tempo do que conforto e felicidade. Assim como o entrevistado H1, vários outros citaram a leveza, sensação de paz, limpeza mental e economia de dinheiro como benefícios ao aderir uma vida minimalista. "Satisfação" foi uma palavra muito utilizada para descrever como se sentem em relação a este estilo de vida, assim como a expressão "vida com propósito", já que os adeptos do minimalismo buscam encontrar um propósito em tudo que fazem. Alguns autores estudaram essas questões. Puls e Becker (2018) mencionam que os minimalistas buscam o que de fato é importante e quais são o sentido e o propósito da vida. Johnston e Burton (2003) também ressaltam que a vida simples envolve uma busca pelo propósito de vida e pelo crescimento pessoal.

Segundo os participantes, ao selecionar melhor as amizades, pessoas que eles seguem nas redes sociais, influências e locais onde frequentam, eles aumentam seu nível de felicidade e sensação de liberdade, pois diminuem a pressão na rotina, além de irem a eventos que realmente querem ir e fazer coisas nas quais veem significado. M8 explica que, ao aceitar um excesso de demandas, o resultado pode ser atender mal a todas elas ou não atender de fato nenhuma. Estas demandas podem ser de trabalho, amizades, objetos ou estar relacionadas a qualquer outra área da vida.

Os entrevistados também comentam que após conhecer a teoria acerca da vida minimalista, passaram a intensificar suas atitudes de consumo consciente, não-desperdício e não-acúmulo. Essas práticas passaram a fazer parte de suas vidas, sendo incorporadas em suas rotinas (Elgin, 2012; Silva et al., 2012; Rojas \& Mocarzel, 2015). Portanto, mesmo aqueles que adotaram a vida simples por questões pessoais, passaram a pensar em um consumo mais consciente, tendo em vista as questões ligadas ao meio ambiente (Silva \& Hor-Meyll, 2016).

Por fim, pode-se verificar que os principais benefícios apontados pelos minimalistas entrevistados foram: economia de dinheiro, melhor uso do tempo, autoconhecimento, menor dependência de bens materiais, mais liberdade, satisfação, limpeza mental, felicidade. Esses benefícios foram mencionados em outros estudos (Elgin \& Mitchell, 1977; Silva et al., 2012; Negretto, 2013; Silva \& Hor-Meyll, 2016; Puls \& Becker, 2018).

\section{Dificuldades}

Duas dificuldades foram as mais apontadas durante a pesquisa. A primeira foi a pressão de consumir exercida por outras pessoas, principalmente pessoas próximas como parentes e amigos. A segunda dificuldade mais citada foi apego a bens materiais, como objetos de valor sentimental.

A entrevistada M2 comenta que desde o primeiro emprego que teve após a graduação, começou a sofrer pressão dos colegas de trabalho para gastar adquirindo diversos itens. Ela guardava seus recursos em uma poupança para quando fosse sair da casa dos pais e para viajar, que era o seu desejo. Mas ela conta que os colegas não aceitavam que ela mantivesse o mesmo celular por muito tempo e a tratavam de forma desagradável por ela escolher usar o transporte público ao invés de adquirir um carro. Na mesma linha, a entrevistada M3 diz que a única dificuldade que teve ao aderir ao minimalismo como estilo de vida foi ter que suportar as provocações feitas pelos parentes e amigos. Ela conta que usa roupas e calçados de brechó e era muito criticada por isso, o que a fazia se sentir envergonhada. A entrevistada M5 concorda neste ponto, ela diz que "às vezes é difícil se fazer entender por quem não concorda ou apenas não leva este estilo de vida". 
Já a entrevistada M1 comenta que existe uma discriminação de acordo com a forma como a pessoa se apresenta, por exemplo: vestindo-se de forma simples ou quando opta por não possuir carro. Ela chega a citar um conhecido que quando vai visitar um cliente aluga um carro, pois sabe que será julgado negativamente se chegar até lá por meios de transporte coletivo, por exemplo, sendo desacreditada a sua capacidade profissional.

A entrevistada M6 afirmou que sua maior dificuldade é se desfazer de objetos aos quais ela atribuiu valor sentimental. Além disso, ela acrescenta que é necessário ter disciplina e muita força de vontade para praticar este estilo de vida e isto nem sempre é fácil. A entrevistada M5 reforça este pensamento, pois também considera difícil se desfazer de alguns objetos, como presentes que tenha recebido no passado. Estas mudanças de hábito muitas vezes incluem aprender a ressignificar a relação que se tem com objetos e isto pode ser difícil para muitos.

Silva e Hor-Meyll (2016) também encontraram em seus estudos que os adeptos de uma vida mais simples são incompreendidos pelas pessoas - familiares e amigos, o que foi chamado de isolamento social. 0 estudo de Silva et al. (2012) também mostrou essa dificuldade, pois é algo que a maior parte da sociedade não pratica e não compreende. Portanto, por mais que seja um estilo de vida que traz felicidade aos seus adeptos e diversos outros benefícios, também existe um outro lado com dificuldades percebidas. Porém, mesmo com essas dificuldades, os entrevistados continuam dispostos a praticar o minimalismo, pois, para eles, é um estilo de vida que lhes dá um propósito de vida com o qual se identificam.

\section{CONSIDERAÇÕES FINAIS}

O presente estudo teve como objetivo investigar qual a motivação que impulsiona uma pessoa a adotar o estilo de vida minimalista e quais são os impactos causados por este estilo de vida no consumo. Para alcançar tal objetivo, foram feitas entrevistas em profundidade com dez membros de um grupo do Facebook chamado "Minimalismo".

Foi observado que existem diversas motivações para aderir ao estilo de vida minimalista, sendo estas mais frequentemente de cunho individual. Cada indivíduo pode ter mais de uma motivação. Geralmente as motivações estão relacionadas aos hábitos aprendidos através da família, bem como a busca pela liberdade e felicidade, além do desejo de ter mais tempo e dinheiro disponíveis, ou seja, motivações pessoais. Secundariamente, foi apontada também a preocupação com o meio ambiente. Os entrevistados para o estudo citaram que se preocupam com os danos que o hiperconsumo causa ao meio ambiente, mas esta motivação não foi colocada como principal.

A escolha pelo estilo de vida minimalista está diretamente relacionada a mudanças no consumo. Os minimalistas deixam de consumir produtos supérfluos com frequência, alguns deles evitando ao máximo consumo que não seja essencial. Passaram a consumir com frequência apenas produtos que consideram necessários e muitas vezes escolhem opções com maior padrão de qualidade para maior durabilidade. Também é possível dizer que eles compram itens de segunda mão e costumam doar ou vender o que não consideram útil. Quando possível, eles preferem consertar produtos a comprar novos.

Ao aderir ao estilo de vida minimalista, foi possível perceber como benefício principal uma vida com mais felicidade e liberdade, além de vantagens como menos uso de tempo e dinheiro com coisas que não trazem satisfação. Foi possível notar que os consumidores minimalistas puderam perceber uma melhora na qualidade de vida de um modo geral, já que relatam ter mais tempo para fazer atividades que gostam e ter mais condições de realizar seus sonhos, como viagens e outras conquistas.

Por outro lado, dificuldades relacionadas ao estilo de vida minimalista também foram notadas. Uma delas é o julgamento por parte de pessoas próximas como amigos e familiares e a pressão que sentem para consumir mais, já que a sociedade cobra isso a todo momento. Outra dificuldade é o grande apego aos bens materiais que tenham valor sentimental para as pessoas que estão começando a aderir à vida minimalista.

Percebe-se que é importante estudar este tema para maior compreensão dos diversos aspectos que se relacionam com o minimalismo no consumo e anticonsumo. A vida simples é um tipo de 
anticonsumo e, ambos os temas carecem de estudos, apesar de estarem chamando a atenção de alguns pesquisadores. Geralmente, o anticonsumo e o minimalismo são estudados de forma separadas, necessitando também de estudos que relacionem os dois. 0 presente estudo trouxe essa contribuição de abordar o minimalismo como um tipo de anticonsumo, complementando os estudos sobre anticonsumo existentes trazendo as práticas de consumo/anticonsumo minimalistas. Os minimalistas buscam reduzir o consumo de forma geral, sendo contra o acúmulo de bens materiais e tendo consciência dos impactos que o consumo provoca no planeta. 0 estudo também identificou que os praticantes do estilo de vida minimalista diminuem o consumo de bens materiais, mas passam a investir em outros pontos como alimentação de qualidade, educação e lazer. Portanto, o consumo não acaba, somente diminui e, por isso, é importante entender a relação dos minimalistas com o consumo para que se saiba o que oferecer e como oferecer a esse público.

\section{Limitações do Estudo e Sugestões para Futuras Pesquisas}

0 estudo possui limitações. Ele está restrito à quantidade de entrevistados que foram recrutados por meio de um grupo sobre o tema numa rede social. Além disso, as entrevistas foram feitas de maneira virtual, pois os entrevistados se encontravam em diversos lugares do Brasil. Porém, apesar da pequena quantidade de entrevistados e das entrevistas terem sido feitas de maneira remota, vale ressaltar que o tema de estudo ainda é novo e o artigo trouxe contribuições para o campo de pesquisa.

Algumas sugestões de futuros estudos são: realizar uma pesquisa quantitativa no grupo do Facebook "Minimalismo", o grupo pesquisado no presente artigo, assim como em outras comunidades virtuais. Interessante também seria fazer pesquisas comparativas entre o Brasil e outros países em relação a como o minimalismo é praticado e investigar quais seriam as melhores ações das empresas para atender esse público.

Um achado importante do presente estudo é que as razões para adotar a vida simples, segundo os entrevistados, envolvem tanto questões de interesses pessoais quanto questões ambientais, apesar de essas últimas não serem as principais. Esse achado abre caminho para novos estudos no sentido de entender o que Cherrier (2009), ao estudar o anticonsumo, chamou de "identidade de herói" e "identidade de projeto". Haveria alguma relação entre a "identidade de herói" de se ver como agente de mudança do mundo e a adoção do minimalismo por motivos ambientais? E "identidade de projeto", no caso do minimalismo, estaria mais ligada a interesses pessoais? São questionamentos que valem ser investigados futuramente: os minimalistas se veem como agentes de mudança do mundo?

Essa questão pode esbarrar também com o que Silva e Hor-Meyll (2016) mencionaram. Segundos os autores, os adotantes da vida simples se diferenciam por meio do não consumo, ou seja, se veem diferentes dos outros por não consumirem. A questão da distinção pelo consumo poderia então, nesse caso, ser também aplicada ao anticonsumo e ao minimalismo? Os anticonsumidores minimalistas se veem como superiores a quem vive uma vida pautada no consumismo? Entender melhor a identidade dos minimalistas poderia trazer grandes contribuições ao campo de estudo.

\section{Referências}

Ahuvia, A. (2008). If money doesn't make us happy, why do we act as if does? Journal of Economic Psychology, 29(4), 491-507.

Almeida, M. (2017). Este documentário da Netflix vai fazer você repensar suas compras. Revista Exame. Disponível em: https://exame.com/seu-dinheiro/este-documentario-da-netflix-vaifazer-voce-repensar-suas-compras/. Acesso: junho de 2020.

Baudrillard, J. (2008). A Sociedade de Consumo. Lisboa: Edições 70.

Buell, L. (2005). Downwardly mobile for conscience's sake: Voluntary simplicity from Thoreau to Lily Bart. American Literary History, 17(4), 653-665.

Candido, L. (2016). Quando Menos é Mais: Olhares, Discursos e Práticas Acerca da "Vida Simples". Dissertação de Mestrado, Programa de Pós-Graduação em Ciências Sociais PUC-RS. 
Chatzidakis, A. \& Lee, M. S. W. (2013). Anti-Consumption as the Study of Reasons against. Journal of Macromarketing, 33(3), 190-203.

Cherrier, H. (2009). Anti-consumption discourses and consumer-resistant identities. Journal of Business Research, 62, 181-190.

Csikszentmihalyi, M. (1999). If We Are So Rich, Why Aren't We Happy? American Psychologist, 54(10).

Elgin, D. (2012). Simplicidade Voluntária: em busca de um estilo de vida exteriormente simples, mas interiormente rico. São Paulo: Cultrix.

Elgin, D. \& Mitchell, A. (1977). Voluntary Simplicity. Te CoEvolution Quarterly, 14.

Etzioni, A. (1998). Voluntary simplicity: Characterization, select psychological implications, and societal consequences. Journal of Economic Psychology, 19, 619-643.

Fraser, M. T. D. \& Gondim, S. M. G. (2004). Da Fala do Outro ao Texto Negociado: Discussões sobre a Entrevista na Pesquisa Qualitativa. Revista Paidéia, 14(28), 2004.

Hogg, M. K., Banister, E. N., \& Stephenson, C. A. (2009). Mapping symbolic (anti-) consumption. Journal of Business Research, 62, 148 - 159.

Hollenbeck, C. K. \& Zinkhan, G. M. (2006). Consumer Activism on the Internet: The Role of Anti-brand Communities. Advances in Consumer Research, 23.

Iyer, R. \& Muncy, J. (2009). A. Purpose and object of anti-consumption. Journal of Business Research, 62, $160-168$.

Johnston, T. C. \& Burton, J. B. (2003). Voluntary Simplicity: Definitions and Dimensions. Academy of Marketing Studies Journal, 7(1).

Lipovetsky, G. (2006). A felicidade paradoxal: ensaio sobre a sociedade do hiperconsumo. Lisboa: 70.

Malhotra, N. (2012). Pesquisa de Marketing: uma orientação aplicada. 6a edição. Porto Alegre: Bookman.

Mendonça, G. O., Rocha, A. R. C., \& Tayt-Son, D. B. C. (2019). O Processo Minimalista: Um Estudo Netnográfico. In: XLIII Encontro da ANPAD. Anais... São Paulo: Anpad.

Negretto, L. (2013). As Relações Entre a Dinâmica Pós-Moderna e o Consumo Minimalista. Disponível em: http://revistaseletronicas.pucrs.br/ojs/index.php/graduacao/article/ view/17827/11456 Acesso em: junho de 2019.

Nicolaci-da-Costa, A. M., Romão-Dias, D., \& Di Luccio, F. (2009). Uso de Entrevistas On-Line no Método de Explicitação do Discurso Subjacente (MEDS). Psicologia: Reflexão e Crítica, 22(1).

Oates, C., McDonald, S., Alevizou, P., Hwang, K., Young, W., \& McMorland, L. (2008). Marketing sustainability: Use of information sources and degrees of voluntary simplicity. Journal of Marketing Communications, 14(5), 351-365.

Pentina, I. \& Amos, C. (2011). The Freegan phenomenon: anti-consumption or consumer resistance? European Journal of Marketing, 45(11/12), 1768-1778.

Puls, L. \& Becker, M (2018). 0 estilo de vida minimalista x consumo do vestuário de moda. E-Revista LOGO, 7(2).

Rojas, A. A. \& Mocarzel, M. M. V. (2015). Da cultura visual à cultura material: o minimalismo como forma de expressão na sociedade de consumo. ALCEU, 16(31).

Shaw, D. \& Newholm, T. (2002). Voluntary Simplicity and the Ethics of Consumption. Psychology \& Marketing, 19(2), 167-185.

Silva, R. C. M., Chauvel, M., \& Macedo-Soares, T. D. (2012). Investigando o comportamento dos consumidores que buscam a simplicidade: Um estudo exploratório. Revista Portuguesa e Brasileira de Gestão, jan/mar.

Silva, R. C. M. \& Hor-Meyll, L. F. (2016). Simplicidade Voluntária: escolhendo uma nova forma de viver. Revista Pretexto, 17(2), 98-116.

Sobreira, E. M. C, Silva, A. L. L., \& Coelho, P. F. C. (2018). Simplicidade Voluntária e Armário-Cápsula: Valores e Motivações no Consumo de Vestuário. Revista de Administração FACES Journal, 17(2), 134-151, abr./jun.

The Orion Publishing Group (2019). Chega de Plástico. Rio de Janeiro: Sextante.

Zavestoski, S. (2002). The social-psychological bases of anti-consumption attitudes. Psychology and Marketing, 19(2), 149-165. 